\title{
Eco-efficiency in Brazilian Amazonian agriculture: opportunity costs of degradation and protection of the environment
}

\author{
Carlos Rosano-Peña ${ }^{1} \cdot$ Joanílio Rodolpho Teixeira ${ }^{2} \cdot$ Herbert Kimura $^{1}$ \\ Received: 6 May 2020 / Accepted: 7 June 2021 / Published online: 1 July 2021 \\ (C) The Author(s), under exclusive licence to Springer-Verlag GmbH Germany, part of Springer Nature 2021
}

\begin{abstract}
Aiming to assist the environmental sustainability of the Brazilian Amazonian agriculture, this article developed an ecoefficiency index, indicating the possible limits to maximize economic and environmental objectives, taking into account the best practices in the municipalities of the region. Shadow prices of degraded areas and forest preservation were also estimated using data envelopment analysis with directional distance functions. The results indicate that, on average, the analyzed municipalities are able to expand the production and the forest areas by $38 \%$ and reduce degraded areas and their inputs in the same proportion. The shadow prices allowed the estimation of the annual opportunity cost of the degraded areas and the preservation of the forest on the farms. The first, US\$3,131,571, represented $0.04 \%$ of the annual output value, indicating that the internalization of that cost should be a low burden for the eco-efficient producer. The second, the total cost of preserving $80 \%$ of the area of property, represented US\$120,890,662 or $1.7 \%$ of the annual income of the biome producers studied. Therefore, the main conclusion of this work is that the internalization of negative and positive externalities of agricultural production in the Amazonian biome does not make agricultural production economically unfeasible in the region. In addition, the reimbursement of damages avoided by carbon sequestration, through the Clean Development Mechanism (CDM) established by the Kyoto Conference, should further increase the economic and environmental sustainability of agriculture in the area.
\end{abstract}

Keywords Data envelopment analysis · Eco-efficiency $\cdot$ Shadow price $\cdot$ Opportunity costs ·

Brazilian Amazonian agriculture

\section{Introduction}

The world's growing concern with environmental problems resulting from the expansion of the agricultural frontier and from the intensification of agricultural production in the

Responsible Editor: Philippe Garrigues

Carlos Rosano-Peña

gmcrosano@gmail.com

Joanílio Rodolpho Teixeira

joanilioteixeira@hotmail.com

Herbert Kimura

herbert.kimura@gmail.com

1 Department of Management, University of Brasília, Campus Darcy Ribeiro, Brasília, Federal District, 70910-900, Brazil

2 Department of Economics, University of Brasília, Campus Darcy Ribeiro, Brasília, Federal District, 70910-900, Brazil
Brazilian Amazonia is notorious. Paradoxically, the Green Revolution in the region largely induced deforestation, loss of biodiversity, pollution and depletion of water resources, desertification and soil erosion, growth of emissions of greenhouse gases, and the risk of global climate change (Barreto et al. 2006).

Nevertheless, Brazil, as one of the world's largest food exporters, faces yet another challenge: the rising global population and undernutrition or malnutrition plaguing millions of people. It is estimated that global agricultural production will have to increase by $70 \%$ to feed a population expected to exceed 9 billion by 2050 (FAO 2009).

To meet this dual challenge, Brazilian agriculture, especially in the Amazonia, must change old strategies and practices into a new paradigm to maintain and expand the achievements of the Green Revolution, while minimizing environmental consequences of this development. In this context, a second and even greener revolution is required.

Therefore, decision makers seek answers from academia for the following questions: Is it possible to, simultaneously, 
maximize economic performance and minimize environmental impacts and use of non-renewable natural resources? How to make the most eco-efficient agriculture? What is the cost of environmental degradation and preservation? Does the internalization of these costs make the region's agricultural production economically unfeasible? Hence, our research problem focuses on finding answers to these questions.

Since the 1980s, in the literature on the production theory, a growing number of articles attempt to address these questions by providing answers resulting from the use and combination of different research methods (Tyteca 1996; Bravo-Ureta et al. 2006; Darku et al. 2013; Caiado et al. 2017). One of these methods follows production theory that uses different approaches, within which it is possible to cite two. The first procedure relates to research addressing the efficient behavior hypothesis of production units as a sine qua non condition to survive in the competitive market and the existence of trade-offs between economic and environmental objectives. This approach uses the traditional production function and the total factor productivity, ignoring the externalities inherent to the process. However, the significant increase of undesirable products or contaminants makes this procedure inadequate. Results can be misleading, since the production units with more restrictions and environmental responsibilities are likely to exhibit lower levels of productivity and efficiency (Pittman 1983; Ball et al. 2005).

This limitation led to the emergence of the second procedure, incorporating the hypothesis of market failures that inhibit efficient behavior. This proposal models a multiproduct technological frontier with desirable and undesirable outputs. Thus, it is possible to find the potential to increase the supply of desirable outputs while minimizing both environmental impact and use of production factors, in a win-win context. This formal technique, as we will discuss in the methodological section, presents some advantages compared with others.

For the latter, there are recent empirical studies using the Shephard distance functions (Lampe and Hilgers 2015). These applications estimate productivity, efficiency, and shadow prices, employing both parametric and nonparametric methods, starting from different assumptions with advantages and disadvantages. The first method basically uses the Stochastic Frontier Analysis (SFA) with a parametric distance function expressing a relationship between outputs and inputs that represents the boundary of the set of production possibilities (PPS). The tool decomposes the deviation from the frontier in stochastic noise and technical inefficiency. The functional relationship is estimated by the maximum likelihood criterium. The second method uses Data Envelopment Analysis (DEA) and
Malmquist Productivity Index (MPI) to model the multiproduct technologies and the internalization of externalities associated with the production process. To minimize possible specification and unknown errors, it uses technology through distance functions, measured as a mathematical programming problem, without the need to predefine a stochastic function of production and the type of distribution or behavior. However, by being deterministic, DEA disregards the influences of the random disturbances of the production process (Simar and Wilson 2007).

These tools are extensively used to study technical efficiency in agriculture. More specifically, some analyses of the ecological efficiency in agriculture include the works of Reinhard et al. (2000) that introduce an environmental impact waste to measure the environmental efficiency of Dutch dairy farms comparing the two methods (SFA and DEA); Areal et al. (2012) that explore parametric distance functions in environmental efficiency of British dairy farms; Färe et al. (2006) that apply deterministic mathematical programming techniques and parametric distance functions to estimate the shadow prices of pollutants and the levels of eco-efficiency of agriculture in the US states. Regarding a nonparametric perspective with mathematical programming, Ball et al. (2005) assess the dynamics of American agriculture, incorporating the environmental impact with the MPI; and Picazo-Tadeo et al. (2011) evaluate eco-efficiency of Spanish agriculture using DEA. However, it is noted that the works are basically focused on estimating the shadow price of environmental degradation. Few studies have focused on assessing the shadow price of positive externalities.

It is important to highlight that the use of these tools to study eco-efficiency and externalities in Brazilian agriculture is still incipient. Regarding the multiproduct stochastic frontier, Peña et al. (2018) used hyperbolic distance functions to estimate the eco-efficiency of Amazonian agriculture. Among works employing non-parametric methods, it is worth mentioning Padrão et al. (2012), comparing the technical and environmental efficiency of agricultural production in the Amazonia and estimating the opportunity cost of the Forest Code using the DEA model.

Filling an important literature gap on eco-efficiency and pricing of externalities in the Brazilian Amazonia, the present study has the following objectives: (i) Initially, to estimate an eco-efficiency indicator for the agriculture in the region that, satisfying the great concept of Pareto, simultaneously maximizes the economic and environmental aims, with reference to best practices in the local municipalities. In this regard, we use the DEA with directional distance functions, exploring classic variables of agricultural activity and internalization of two externalities (one positive and another negative). (ii) Subsequently, after the virtual 
correction of eco-inefficiency, we estimate the shadow prices of externalities, taking advantage of the slope of the projection on the eco-efficient production frontier and the properties of duality of DEA linear programming problems. In this calculation, the use of the DEA method has it advantages compared to the parametric one, since it allows finding the shadow prices of each unit evaluated. The latter allows calculating the opportunity costs of degraded land and forest preservation, while testing the feasibility of internalization of detected externalities.

After the present introduction, our research is structured as follows: "Methodology" provides a review of concepts and measures of efficiency and shadow price; "Agrarian system object of study and variables" describes the object and the study parameters; "Results" shows the results of the study; finally, "Conclusions" presents the main conclusions.

\section{Methodology}

Farming is a multifunctional activity with a strong impact on the ecosystem. It uses a set of production factors, including natural resources, and generates two types of complementary products. One of them is intended to satisfy human needs (food and raw materials) and is associated primarily with market and price mechanisms. The other is the side effect imposed on third parties not included in the individual cost of production, due to lack of market and well-defined property rights. Not internalized in the cost, the second type of product relates to externality, which can be negative (unwanted or undesirable), when generating costs for society (e.g., pollution, biodiversity loss, and soil degradation), or positive (desirable), when generating social benefits, such as ecosystem services in areas of environmental preservation of rural properties (PicazoTadeo et al. 2011).

The technology used in farming is peculiar to each crop or situation. Therefore, the generic way to describe the technology is the production possibilities set (PPS). This set includes vectors used inputs $\left(\boldsymbol{x} \in R_{+}^{n}\right)$ and outputs produced $\left(\boldsymbol{u} \in R_{+}^{m}\right)$ in $i$ Decision Making Units (DMUs) within a certain time. The outputs $\boldsymbol{u}=(\boldsymbol{y}, \boldsymbol{b})$ are segregated, where $\boldsymbol{y}$ is the desired output subvector, with $p$ elements; $\boldsymbol{b}$ is the bad or undesirable outputs vector, with $q$ elements, and $m=p+q$. Formally, $P P S=\{(\boldsymbol{x}, \boldsymbol{y}, \boldsymbol{b}): \boldsymbol{x}$ can produce $(\boldsymbol{y}, \boldsymbol{b}) \wedge \boldsymbol{x}, \boldsymbol{y}, \boldsymbol{b} \geq 0\}$

In addition to the classical properties formulated by Grosskopf (1986), the PPS must meet three additional ones, as indicated by Picazo-Tadeo et al. (2012):

(i) The economic activities always generate impacts on the ecosystem, so that the only alternative to not polluting the environment is not producing. That is, both outputs are complementary and there is no technology that is a $100 \%$ clean. This property is called null jointness.

(ii) Existing ecological efficiency, the reduction of both types of outputs is possible, but isolated elimination of unwanted products is impossible. This means that the elimination of pollutants involves compensation (trade off), a cost measured in terms of opportunities as the value at which the output $(y)$ must be reduced to mitigate the environmental impact $(b)$. This unit value is called the shadow price and represents the unit cost of environmental degradation to the producer, according to Färe and Grosskopf (2000). This property is called weak disposability of outputs.

(iii) In the absence of eco-efficiency, it is possible to generate a larger number of pollutants $(b)$ with the same amount of $x$ and $y$. Therefore, the reduction of the undesirable output does not imply a decrease of desirable product and the opportunity cost of reducing the environmental impact is zero. This property is named strong disposability of desired outputs.

The PPS properties determine a multidimensional space and a frontier comprised the axes of the variables involved $(\boldsymbol{x}, \boldsymbol{y}, \boldsymbol{b})$.

The frontier corresponds to the largest allowable desired output with certain levels of input and undesirable product; alternatively, the smaller amount of inputs and by-products possible to bring out a given output vector. This means that eco-efficient DMUs form the frontier of the PPS and there is only weak disposability. The subset of inefficient units is located between the frontier and the axes, showing strong disposability. Therefore, eco-inefficiency of a DMU can be measured by its distance to the frontier. In other words, one can measure the eco-inefficiency of a DMU by comparing its performance with best practices.

In this vein, we can reason the concept of eco-efficiency as the ability of both, a company or an economy (DMU), to produce a given amount of desirable output with the least amount of inputs and environmental impact. Similar is the ability to maximize production with a given quantity of inputs and unwanted by-products. Thus, the optimal ecoefficiency, associated with a given combination of inputs, is achieved in the efficient frontier of the PPS. It is an optimal point of Pareto, when no other production process or combination of processes can give rise to the same output level, impacting less environment and using less inputs (Kuosmanen and Kortelainen 2005).

Notice that, necessarily, eco-efficiency is not sufficient to achieve sustainability (Callens and Tyteca 1999). This occurs because the minimum values of environmental impact of eco-efficiency are determined relatively to a sample of DMUs, not to the universe, and disregard the planet's ability 
to absorb and support this minimum value. Furthermore, the concept of sustainability is broader, including social aspects (WCED 1987).

One of the most appropriate models for characterizing the PPS and estimating the eco-efficiency measures is the directional distance function, developed by Chung et al. (1997) and Färe and Grosskopf (2000), to include unwanted products. The directional distance function is one of the most flexible way to optimize multiple goals. It allows, by defining a priori different projection directions on the efficient frontier by a directional vector $(g=$ $\left.-g_{x}, g_{y},-g_{b}\right)$, to offer a range of options to meet the ecological efficiency. This can also improve a group of variables without affecting the behavior of others. The relationship explicitly shows the favorable accomplishment of the method used, compared with other.

The directional distance function can be expressed as follows (Chung et al. 1997; Färe and Grosskopf 2000):

$$
\begin{aligned}
& \vec{D}\left[\boldsymbol{x}, \boldsymbol{y}, \boldsymbol{b} ;\left(-g_{x}, g_{y},-g_{b}\right)\right] \\
& =\operatorname{Max}\left\{\beta:\left(\boldsymbol{x}-\beta g_{x}, \boldsymbol{y}+\beta g_{y}, \boldsymbol{b}-\beta g_{b}\right) \in P P S\right\}
\end{aligned}
$$

In expression (1), the parameter $\beta$ is the optimum value to be estimated, when the direction of the vector, a priori defined by the researcher, is $\left(-g_{x}=1, g_{y}=1,-g_{b}=1\right)$. It indicates the maximum attainable expansion of desirable outputs in the $g_{y}$ direction. It is also the largest feasible contraction of undesirable outputs in the $g_{b}$ direction and inputs in the $g_{x}$ direction. Therefore, $\beta \geq 0$. If $\beta=0$ it means that the unit is efficiently evaluated; if $\beta>0$ it is inefficient.

Figure 1 graphically illustrates different projections on the border of an inefficient unit $(A)$ which, using a given level of inputs, produces a desirable output $(y)$ as well as an undesired by-product $(b)$. The directional output distance function can use three different directional vectors given in Eq. 2, in order to project the point $A$ on the efficient frontier. It is observed that, for each vector, the directional distance functions are projecting $A$ to the efficient $\operatorname{arcST} R$, which implies an increase of $y$ and/or a decrease in $b$, satisfying the Pareto optimal. Furthermore, as the different directions lead to specific points on the border, each has a different tangent. Thus, these points will not have equal marginal rates of substitution and shadow prices. Note that, the lesser the pollution of a DMU, the greater must be the slope of the tangent and the shadow price.

$$
\begin{aligned}
\vec{D}[x, y, b ;(0,1,0)]= & \operatorname{Max}\left\{\beta:\left(c, y+\beta g_{y}, b\right) \in C P P\right\} \\
\vec{D}[x, y, b ;(0,1,-1)]= & \operatorname{Max}\left\{\beta:\left(c, y+\beta g_{y}, b\right.\right. \\
& \left.\left.-\beta g_{b}\right) \in C P P\right\} \\
\vec{D}[x, y, b ;(0,0,-1)]= & \operatorname{Max}\left\{\beta:\left(c, y, b-\beta g_{b}\right) \in C P P\right\}
\end{aligned}
$$

In estimating the shadow price of undesirable by-product, an important property of the directional distance function

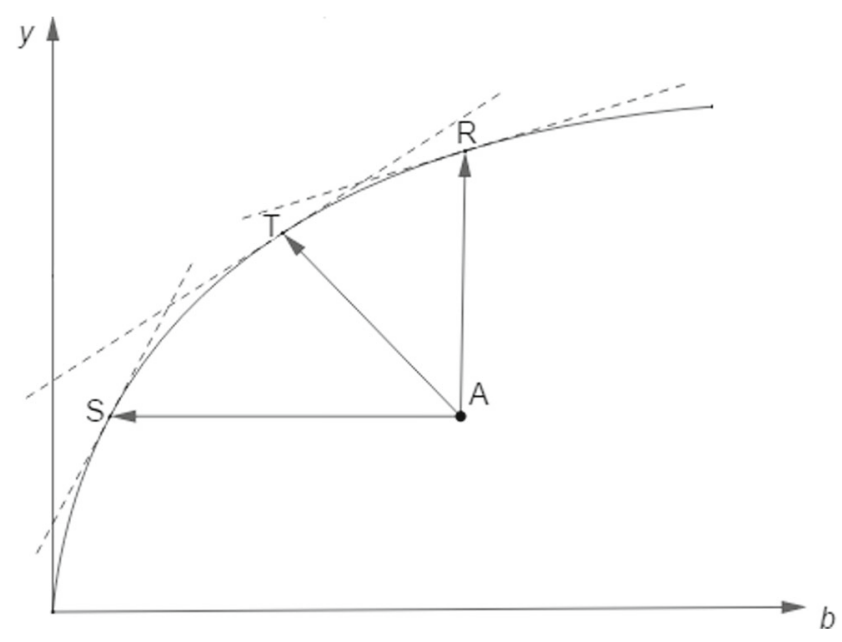

Fig. 1 The efficient frontier of the PPS and different projections of the directional output distance function

lies in its duality (Lee et al. 2002; Färe and Grosskopf 2005). According to this property, the solution of the profit-maximization problem can be found from the distance function to outputs given by the following linear programming problem (LPP) depicted in Eq. 3:

$$
\begin{array}{r}
\operatorname{Max}_{\boldsymbol{x}, \boldsymbol{y}, \boldsymbol{b}} \boldsymbol{P}_{\boldsymbol{y}} \boldsymbol{y}^{\prime}-\boldsymbol{P}_{\boldsymbol{b}} \boldsymbol{b}^{\prime}-\boldsymbol{P}_{\boldsymbol{x}} \boldsymbol{x}^{\prime} \\
\text { s.t. } \\
\vec{D}_{o}\left[\boldsymbol{x}, \boldsymbol{y}, \boldsymbol{b} ;\left(-g_{x}, g_{y},-g_{b}\right)\right]=1
\end{array}
$$

where $\boldsymbol{P}_{y}$ and $\boldsymbol{P}_{x}$ are the price vectors (assumed to be the market price) of the desirable outputs and inputs respectively and $\boldsymbol{P}_{b}$ is the shadow price of undesirable products. The Lagrangian function (3) is:

$$
\mathcal{L}=\boldsymbol{P}_{\boldsymbol{y}} \boldsymbol{y}^{\prime}-\boldsymbol{P}_{\boldsymbol{b}} \boldsymbol{b}^{\prime}-\boldsymbol{P}_{\boldsymbol{x}} \boldsymbol{x}^{\prime}+\lambda\left(\vec{D}_{o}\left[\boldsymbol{x}, \boldsymbol{y}, \boldsymbol{b} ;\left(-g_{x}, g_{y},-g_{b}\right)\right]-1\right)
$$

The first-order conditions are:

$$
\begin{gathered}
\frac{\partial \mathcal{L}}{\partial \boldsymbol{y}}=\lambda \frac{\partial \vec{D}_{o}\left[\boldsymbol{x}, \boldsymbol{y}, \boldsymbol{b} ;\left(-g_{x}, g_{y},-g_{b}\right)\right]}{\partial \boldsymbol{y}}=0 \\
\frac{\partial \mathcal{L}}{\partial \boldsymbol{b}}=\lambda \frac{\partial \vec{D}_{o}\left[\boldsymbol{x}, \boldsymbol{y}, \boldsymbol{b} ;\left(-g_{x}, g_{y},-g_{b}\right)\right]}{\partial \boldsymbol{b}}=0
\end{gathered}
$$

$$
\frac{\partial \mathcal{L}}{\partial \boldsymbol{x}}=\lambda \frac{\partial \vec{D}_{o}\left[\boldsymbol{x}, \boldsymbol{y}, \boldsymbol{b} ;\left(-g_{x}, g_{y},-g_{b}\right)\right]}{\partial \boldsymbol{x}}=0
$$

$\frac{\partial \mathcal{L}}{\partial \lambda}=\partial \vec{D}_{o}\left[\boldsymbol{x}, \boldsymbol{y}, \boldsymbol{b} ;\left(-g_{x}, g_{y},-g_{b}\right)\right]-1=0$

We assume here that the second-order conditions are satisfied under the shape of quasi-concavity of the directional outputs distance function. From the solution of Eq. 4, the relative shadow price of an undesirable product and a 
desirable product is deduced using the ratio of the first order conditions (6) and (5), namely:

$$
\begin{aligned}
\frac{P_{b}}{P_{y}} & =\frac{\partial \vec{D}_{o}\left[x, y, b ;\left(-g_{x}, g_{y},-g_{b}\right)\right] / \partial b}{\partial \vec{D}_{o}\left[x, y, b ;\left(-g_{x}, g_{y},-g_{b}\right)\right] / \partial y} \therefore \\
P_{b} & =P_{y} \frac{\partial \vec{D}_{o}\left[x, y, b ;\left(-g_{x}, g_{y},-g_{b}\right)\right] / \partial b}{\partial \vec{D}_{o}\left[x, y, b ;\left(-g_{x}, g_{y},-g_{b}\right)\right] / \partial y}
\end{aligned}
$$

The shadow price of undesirable output can be interpreted as the opportunity cost of reducing an additional unit of environmental impact in terms of loss of a desirable product, keeping constant the level of eco-efficiency and the behavior of other variables.

Similarly, one can infer the shadow price of a positive externality $\left(y_{2}\right)$. It expresses the loss of potential gain by the choice to increase the generation of positive externality. It also defines the marginal rate of transformation of the desirable product. This shadow price is explained as

$$
\begin{aligned}
\frac{P_{y_{2}}}{P_{y_{1}}} & =\frac{\partial \vec{D}_{o}\left[x, y, b ;\left(-g_{x}, g_{y},-g_{b}\right)\right] / \partial y_{2}}{\partial \vec{D}_{o}\left[x, y, b ;\left(-g_{x}, g_{y},-g_{b}\right)\right] / \partial y_{1}} \therefore \\
P_{y_{2}} & =P_{y_{1}} \frac{\partial \vec{D}_{o}\left[x, y, b ;\left(-g_{x}, g_{y},-g_{b}\right)\right] / \partial y_{2}}{\partial \vec{D}_{o}\left[x, y, b ;\left(-g_{x}, g_{y},-g_{b}\right)\right] / \partial y_{1}}
\end{aligned}
$$

Shadow prices can offer a solution to the complex problem, hitherto unresolved, of building the function of demand and supply for environmental goods and services. On the one hand, by associating the shadow price $P_{b}$ and the levels of degradation, the demand for preservation function can be estimated. Given this function and a range $(a, b)$, the defined integral estimates the total cost of degradation. In the interval, $a$, the lower limit of the integral, can indicate the maximum tolerable level of degradation and $b$ is the actual maximum limit of degradation. This makes it possible to estimate both the degradation cost of each production unit and that of the region as a whole. In contrast, associating the shadow price $P_{y_{2}}$ and preservation levels results in the offer for environmental services. Based on the same procedure with the offer function and the interval, the total cost of preservation is estimated.

Distance functions and shadow prices can be estimated with parametric and non-parametric methods. As mentioned earlier, we use the non-parametric method DEA. An important advantage of this method, compared to the parametric one, is that the estimate of shadow prices is simple, direct, and individualized, making it possible to obtain measurements for each DMU. In this application, eco-efficiencies and shadow prices can be obtained for each DMU from the calculation of the following linear programming problem (LPP):

$\vec{D}_{o}=\left(\boldsymbol{x}, \boldsymbol{y}, \boldsymbol{b} ;-g_{x}, g_{y},-g_{b}\right)=\operatorname{Max}(\beta)$ subject to:

$$
\begin{aligned}
& \left(1+\beta g_{y}\right) \times \boldsymbol{y}^{i} \leq \boldsymbol{Y}_{z} \\
& \left(1-\beta g_{b}\right) \times \boldsymbol{b}^{i}=\boldsymbol{B}_{\boldsymbol{z}} \\
& \left(1-\beta g_{x}\right) \times \boldsymbol{x}^{i} \geq \boldsymbol{X}_{\boldsymbol{z}}
\end{aligned}
$$

$z \geq 0$

As already seen, $\boldsymbol{x}^{i}, \boldsymbol{y}^{i}$, and $\boldsymbol{b}^{i}$ denote, respectively, the vector of inputs, desirable outputs, and undesirable outputs of the $i$-th DMU evaluated. $\boldsymbol{X}, \boldsymbol{Y}$, and $\boldsymbol{B}$ are, respectively, the matrices of the inputs: desirable outputs and undesirable outputs of the evaluated DMUs; $z$ is a vector of intensities used to weight the DMUs in the definition of the reference frontier.

The equivalent to $z$ in the dual of linear programming problem (11) indicates the absolute dual price for each output and each input in determining the eco-efficiency. It shows how much eco-efficiency can be increased if a unit raised desired output or reduced environmental impacts and inputs. The absolute dual prices of the constraints (12) and (13) are $\partial \vec{D}_{o}\left[x, y, b ;\left(-g_{x}, g_{y},-g_{b}\right)\right] / \partial y$ and

$\partial \vec{D}_{o}\left[x, y, b ;\left(-g_{x}, g_{y},-g_{b}\right)\right] / \partial b$, respectively. It is expected that the first absolute dual price be non-negative, since an increase of $y$ should expand the eco-efficiency. In contrast, it is expected that the second be non-positive, since a reduction in emissions should increase that environmental economic performance. Therefore, it is assumed nonpositive dual price on Eqs. 9 and 10.

Weak disposability and null-jointness properties are imposed in expression (11) through the strict equality (=) of the undesirable outputs constraint (restriction (13)). These properties allow the accurate estimation of the shadow prices when the LPP and its border take the pattern depict in Fig. 1.

At this point, it is important to consider what happens if the PPS is represented in Fig. 2, where the biggest producer is not the biggest polluter; i.e., when there is a set of superpolluting DMUs? We call super-polluting those units that use obsolete technologies and, for a given input level, give off more than the most polluting efficient unit.

In Fig. 2, the PPS is described with a desired output $(y)$ on the ordinate, and a pollutant $(b)$ on the abscissa, for a given level of input $(x)$. Thus, $A, B, C, D, E, F$ are the extreme points forming the boundary of the PPS and units which maximize $y$ for a given level of $b$. However, only $A, B, C, D$ form the eco-efficient frontier, where $D$ is the efficient unit with the highest emission level. All units to the right of $D$ can be considered super-polluting units and, in this sense, the $b_{D}$ level can be used to set the maximum 


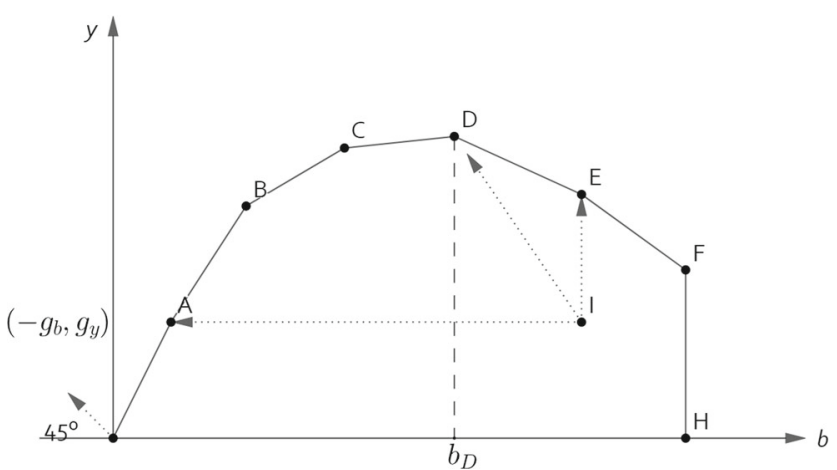

Fig. 2 PPS with super-polluting units and downward-sloping segments

pollution, as it does not compromise the efficiency and maximum productivity.

According to Picazo-Tadeo and Prior (2009), when the PPS includes super-polluting units, the LPP (11) should consider the points $E$ and $F$ eco-efficient because they are extreme positions. In addition, the LPP will project point $I$ in the end of segment $\overline{D E}$, with negative slope. Thus, the relative shadow price of pollution $(b)$ and the marginal rate of substitution between desired and undesired products of points $E, F$, and $I$, will be positive. In other words, ecoefficient units can increase an environmental degradation while reducing the desirable production. This contravenes the optimum principle in the sense of Pareto.

To correct this problem, Arandia and Aldanondo-Ochoa (2011), according to Färe et al. (2006), we treat pollution as input and exchange constraints (13) through (18) as in the following LPP:

$\vec{D}_{0}=\left(\boldsymbol{x}, \boldsymbol{y}, \boldsymbol{b} ;-g_{x}, g_{y},-g_{b}\right)=\operatorname{Max} \beta$

subject to:

$\left(1+\beta g_{y}\right) \times \boldsymbol{y}^{i} \leq \boldsymbol{Y}_{z}$

$\left(1-\beta g_{b}\right) \times \boldsymbol{b}^{i} \geq \boldsymbol{B}_{z}$

$\left(1-\beta g_{x}\right) \times \boldsymbol{x}^{i} \geq \boldsymbol{X}_{z}$

$z \geq 0$

This model will project the inefficient units and superpolluters in the efficient frontier; however, it can give those provisions a null shadow price. To alleviate this problem, the LPP (16) was carried out a second time, after projecting the inefficient units in the border considering the existing slacks.

\section{Agrarian system object of study and variables}

The present research targets farming in the 528 Brazilian municipalities, comprising the Amazonian biome, according to the Ministry of Environment of Brazil. This biome is a set of regions interconnected by the Amazon Rain Forest and the river basin of the Amazon River. Its huge area (4.1 million $\mathrm{km}^{2}$, or $49.9 \%$ of the Brazilian territory) shelters 21 million people living in towns and villages in nine states (Acre, Amapá, Amazonas, Pará, Rondônia, Roraima, Tocantins, Maranhão, and Mato Grosso).

From the 1970s, the public policies of tax incentives, land grant, infrastructure construction, and deployment of technologies have transformed the Amazonia into one of the major expanding agricultural frontiers in Brazil.

In the 1990s, the suspension of tax and financial subsidies established a market-driven economy. The agricultural censuses show that, from 1995 to 2006, growth rates in the Amazonia were higher than other Brazilian regions. This rapid growth took place mostly from cattle farming and soybean production. In the intercensal period, cattle herds increased 59.3\%, reaching 57 million heads, requiring on average 1 ha of pastures (natural and cultured) per animal. In the same period, soybean planted area grew $38 \%$ to 4.4 million ha, yielding around 2.550-3.000 t/ha (Domingues and Bermann 2012).

According to the Institute of Applied Economic Research (IPEA 2013), the low price of land and increasing demand on domestic and foreign markets also explain the rapid growth of agriculture endeavors in the zone. The factors above increased the region's competitiveness, even with higher operational, logistic costs, and intensive agrochemicals to correct the low natural soil fertility. The 2006 agricultural census (IBGE 2010) also shows a high concentration of land in the region. In 2006, properties with less than 100 ha represented $72.7 \%$ of total and occupied only $13.1 \%$ of the total studied area, while those larger than 1000 ha, made up $2.1 \%$ representing $58.7 \%$ of the total area.

This unequal distribution explains the heterogeneous technology used in the Amazonian agriculture. Firstly, producers with high expertise using capital-intensive technologies, making transplant embryos and genetic selection of high-yielding matrixes, use the latest technologies. This is peculiar in the Amazonian region of Mato Grosso. On the other hand, a large majority of small producers use outdated, predatory technologies, such as slash and burn.

According to the National Institute of Amazonian Research (Val and Santos 2011), small producers commonly use itinerant plantation. It begins clearing 1 to 2 ha of forest, sale of fine wood and fire. At first, fire increases 
soil fertility and allows crops for $2-3$ consecutive years. However, as fertility decreases significantly, it is common to leave the area fallow for 10 years and deforest and burn a new 1- or 2-ha tract. This cycle ends with the farmer returning to the starting area, to burn vegetation regenerated in the fallow time. This practice of rotation has three undesirable consequences: (i) requires 6 times more land than actually planted; (ii) leads, regularly, to deforestation of more than the $20 \%$ limit defined by the Forest Code; (iii) the land, bare of forest cover and organic matter, rapidly depletes. High rainfall and high temperatures year-round force land abandonment, since the cost recovery is higher than the acquisition of new areas (Val and Santos 2011).

However, deforestation, burning, and soil degradation are not exclusive to small producers. The 2006 census confirms that $28 \%$ of the areas of rural properties in the study are degraded lands. This value is larger than the total area of small farms (13.1\%), as previously seen. Therefore, it is not appropriate to target solely small farmers as the main actors of deforestation, burning, and soil degradation.

The World Bank supports this conclusion by pointing to large- and medium-sized livestock as the main responsible for environmentally adverse practices (Margulis 2003), motivated by the high profitability of Amazonian livestock related to traditional regions. It is important to highlight that the study of land degradation is a current research theme, as explored in Graves et al. (2015), Reed et al. (2015), Sutton et al. (2016), Medrilzam et al. (2017), Kust et al. (2017), and Aladejana et al. (2018).

The empirical analysis is based on the 2006 agricultural census (IBGE 2010), available when we started this investigation. The research considered the 528 municipalities that make up the Amazonian region in the Brazil. We use, as in most of the cases studied by Suzigan et al. (2020) in their review of the literature, the standard inputs and outputs of the agricultural sector. Here, we have innovated the analysis by incorporating both positive and negative externalities to estimate eco-efficiency and not only the opportunity cost of degradation, but also the opportunity cost of preservation.

The inputs used in the model were as follows: $\boldsymbol{x}_{\mathbf{1}}$, property labor in number of workers; $\boldsymbol{x}_{\mathbf{2}}$, capital estimated by the depreciation, $10 \%$ of the value of fixed assets in US\$; $\boldsymbol{x}_{\mathbf{3}}$, total area (ha) of the establishments; $\boldsymbol{x}_{\mathbf{4}}$, other current expenditure called spending on costing in US\$. The outputs consider three types of products: $\boldsymbol{y}_{\mathbf{1}}$, desirable product, total value of production in US\$; $\boldsymbol{y}_{\mathbf{2}}$, environmental desirable product, forest areas and natural forests (ha) preserved in properties; $\boldsymbol{b}_{\mathbf{1}}$, environmental undesirable product, areas of degraded lands (ha) in the properties (census does not include abandoned land).

\section{Results}

From data described in the previous section, we reached the results analyzed in two parts. The first examined the ecoefficiency indexes. The second the shadow prices and costs of conservation and environmental degradation.

\section{Eco-efficiency index}

For every 528 municipalities, eco-efficiency indexes were obtained by solving the LPP depicted in Eq. 16. Table 1 shows results aggregated by states, in which the state of Acre is the most eco-efficient, and Maranhão and Tocantins the most eco-inefficient. Mato Grosso boosts the most ecoefficient municipalities (13). Analogous results were found by Pena et al. (2018) who estimated the agricultural ecoefficiency in the Amazonia, using other tool (functions of hyperbolic distances with stochastic frontier).

Note, also, that $38.2 \%$ is the average eco-efficiency rate of all municipalities in the Amazonia biome. This value suggests that, on average, they may increase the total output value $\left(\boldsymbol{y}_{1}\right)$ and the areas intended for forest $\left(\boldsymbol{y}_{\mathbf{2}}\right)$ by $38.2 \%$ and reduce degraded areas and inputs, in the same amount. According to such results, if the world production of food is expected to increase $70 \%$ by 2050 to meet world's population, in 2006, the studied municipalities would have reached more than half of this target by only imitating the local best practices in 35 eco-efficient DMUs. In addition, the eco-efficiency would improve compliance of areas of preserved forests stipulated by the Forest Code. According to 2006 census, only 10 municipalities in the Amazonia preserve areas larger than, or equal to, $80 \%$, the minimum percentage required by law.

Table 2 shows the absolute values of the improvements required for the eco-efficiency of the Amazonian municipalities grouped by states. These results were obtained considering both the eco-efficiency indexes $(\beta)$ and the slacks estimated by the LPP (16). The Pará state boosts the highest number of eco-inefficient municipalities. Therefore, its potential for improvement is greater. In the opposite direction, Amapá is the state with the least potential for improvement. The reduction in economic and environmental resources is substantial. The growth potential of production and conservation areas are no less relevant (US\$ $1,983,845.28$ thousand and 7 million ha, respectively). It is important to note that the degraded areas would be reduced by 23,498 ha $(124,212.82-100,713.95)$.

\section{Shadow price and opportunity cost}

Here, we begin with the analysis of results of shadow prices obtained by running the LPP (16) twice. The 
Table 1 Mean eco-efficiency indexes in\% of municipalities by states

\begin{tabular}{llll}
\hline States (number of municipalities belonging to the biome) & Average & Standard deviation & No. of eco-efficient municipalities \\
\hline Acre (22) & 17.96 & 0.1390 & 2 \\
Amapá (16) & 19.27 & 0.1625 & 4 \\
Amazonas (62) & 30.24 & 0.2188 & 2 \\
Maranhão (102) & 60.0 & 0.2047 & 13 \\
Mato Grosso (86) & 26.51 & 0.2144 & 0 \\
Pará (143) & 34.55 & 0.1856 & 2 \\
Rondônia (52) & 44.88 & 0.1519 & 0 \\
Roraima (15) & 26.21 & 0.2175 & 35 \\
Tocantins (30) & 50.71 & 0.1379 & 0.2321 \\
Amazon biome as a whole (528) & 38.20 & & \\
\hline
\end{tabular}

first calculation measured the eco-efficiency indexes and improvements that project the inefficient units on the border, presented in the previous sub-section. After correcting inefficiency, the second turn allowed to estimate the absolute and relative shadow prices of degradation and protection of the environment. This procedure reduces the slacks of variables involved and the number of shadow prices with null value. In this way, the two shadow prices of degradation and protection of the environment indicate the marginal revenue that each eco-efficient municipality has to renounce: (1) to reduce an additional unit of degraded area and (2) to increase an additional unit of forest.

Table 3 shows the results of synthesized relative shadow prices of degraded areas and total costs.

The results of shadow prices for degradation provide empirical evidence. First, as expected, none of their values was positive, indicating that with eco-efficiency, reduction of the degraded area is incompatible with the expansion of production. Second, we observe a large dispersion around the mean, with standard deviation of 50,662.90. This is explained by the wide variation in the slope of the efficient frontier of the PPS towards $y_{1}$ and $b_{1}$. Third, there is a downward trend in the shadow price. On the one hand, municipalities with low levels of degraded lands have more inclined tangents and tend to have high shadow prices, confirming that the producer has to make a greater effort to reduce these prices. On the other hand, counties with high levels of degradation exhibit descending slope and lower shadow prices, which may be zero. This indicates that they have negligible costs to reduce degradation. When the slope and hence the shadow price are zero, the evaluated units show slacks. They are found in the so-called weak efficiency frontier and can be categorized as super polluters.

Table 3 indicates that the municipalities of the state of Pará have the highest average shadow price, compared to the counties of other states. In contrast, Amapá has the lowest average in the shadow price. The explanation lies in the fact that the state had the highest level of degraded area relative to the level of production. Table 3 also shows that the regional average was US\$ 3208.85/ha. It seems that averages are overvalued, as they are strongly influenced by the high values of shadow prices in municipalities with

Table 2 Improvements to the efficiency of biome municipalities by states

\begin{tabular}{|c|c|c|c|c|c|c|c|}
\hline States & $\begin{array}{l}x_{1} \text {-Labor (peo- } \\
\text { ple) }\end{array}$ & $\begin{array}{l}\boldsymbol{x}_{\mathbf{2}} \text {-Capital } \\
\text { (1000 US\$) }\end{array}$ & $\boldsymbol{x}_{\mathbf{3}}$-Area (ha) & $\begin{array}{l}\boldsymbol{x}_{\mathbf{4}} \text {-Costing } \\
(1000 \text { US\$) }\end{array}$ & $\begin{array}{l}\boldsymbol{b}_{\mathbf{1}} \text {-Degraded } \\
\text { Areas (ha) }\end{array}$ & $\begin{array}{l}\boldsymbol{y}_{2} \text {-Preserved } \\
\text { Areas (ha) }\end{array}$ & $\begin{array}{l}\boldsymbol{y}_{\mathbf{1}} \text {-Production } \\
\text { (1000 US\$) }\end{array}$ \\
\hline Rondônia & $-130,800.15$ & $-280,133.7$ & $-347,4587.65$ & $-178,960.96$ & $-6,376.32$ & $1,028,878.72$ & $309,087.97$ \\
\hline Acre & $-28,778.29$ & $-55,008.9$ & $-529,741.52$ & $-15,078.56$ & $-3,381.55$ & $269,945.07$ & $33,633.82$ \\
\hline Amazonas & $-134,792.49$ & $-36,478.4$ & $-971,469.70$ & $-34,133.46$ & $-5,096.36$ & $320,880.89$ & $91,409.50$ \\
\hline Roraima & $-6,581.93$ & $-12,976.2$ & $-526,641.10$ & $-9,086.84$ & -755.65 & $142,373.22$ & $12,190.41$ \\
\hline Pará & $-325,139.82$ & $-381,758.8$ & $-8,248,000.02$ & $-395,928.99$ & $-46,962.56$ & $2,481,080.91$ & $653,702.29$ \\
\hline Amapá & $-4,502.20$ & $-3,378.9$ & $-154,937.91$ & $-1,675.67$ & -823.70 & $37,819.02$ & $3,572.32$ \\
\hline Tocantins & $-23,490.21$ & $-61,202.8$ & $-1,405,944.80$ & $-63,906.42$ & $-1,438.19$ & $284,956.61$ & $80,577.82$ \\
\hline Maranhão & $-312,913.19$ & $-93,101.6$ & $-3,208,110.30$ & $-110,906.20$ & $-8,411.70$ & $429,240.23$ & $344,415.38$ \\
\hline Mato Grosso & $-65,975.11$ & $-338,531.9$ & $-6,583,662.66$ & $-1,045,717.69$ & $-27,467.93$ & $2,157,065.46$ & $455,255.48$ \\
\hline Biome Total & $-1,032,973.39$ & $-1,262,571.2$ & $-25,103,095.66$ & $-1,855,394.78$ & $-100,713.95$ & $7,152,240.14$ & $1,983,845.28$ \\
\hline
\end{tabular}


Table 3 Shadow price and costs of degraded areas in the Amazonia

\begin{tabular}{lllll}
\hline States & $\begin{array}{l}\text { Average of Shadow } \\
\text { Price of the Degraded } \\
\text { Area at US\$ / ha }\end{array}$ & $\begin{array}{l}\text { Costs of Degraded } \\
\text { Areas (US\$) }\end{array}$ & $\begin{array}{l}\text { Current Degraded } \\
\text { Areas (ha) }\end{array}$ & $\begin{array}{l}\text { Cost of Degraded Areas } \\
\text { per Hectare at US\$ }\end{array}$ \\
\hline Rondônia & 558.10 & $220,261.70$ & $6,823.62$ & 32.28 \\
Acre & 467.98 & $122,123.23$ & $3,728.10$ & 32.76 \\
Amazonas & 833.39 & $193,337.46$ & $5,961.82$ & 32.43 \\
Roraima & $1,001.62$ & $32,383.09$ & 875.00 & 37.01 \\
Pará & $9,147.74$ & $1,258,881.68$ & $51,531.85$ & 24.43 \\
Amapá & 108.38 & $55,577.78$ & $1,668.36$ & 33.31 \\
Tocantins & $3,705.86$ & $64,917.69$ & $1,590.11$ & 40.83 \\
Maranhão & 262.24 & $340,378.92$ & $10,482.82$ & 32.47 \\
Mato Grosso & $1,633.47$ & $843,709.50$ & $41,551.14$ & 25.21 \\
Biome Total & $3,208.85(50,662.90)$ & $3,131,571.06$ & $124,212.82$ & 25.21
\end{tabular}

low levels of degraded land. Thus, these unit prices should not be multiplied by the degraded areas to find the cost of degradation.

The total cost of degradation is understood as the sum of the marginal revenues that the producer has to give up in order to reduce an additional hectare of degraded land, up to reduce to zero this degradation. Thus, this cost was calculated using the following procedure. (i) Initially, the ordered pairs (level of degraded area - shadow price) were plotted on a graph and the central trend curve was estimated. This curve $P_{d}=f(b)$ finds the best fit that approximates the point cloud described in the diagram. The resulting equation for the curve was $P_{b}=114.56\left(b^{-0.275}\right)$. It expresses the average value of shadow prices for each level of degraded land and indicates that these prices fall at a rate of 0.275 with one hectare of degraded land increase. (ii) Subsequently, the defined integral of the function $P_{d}=f(b)$ was calculated in the interval $(0.1$, value of the degraded area of the municipalities in ha). This calculation resulted in the total costs of degraded land recorded in the third column of Table 3. Since this value represents the additional cost to produce without degrading the land, it must be assumed by the producer, provided that the degradation is prohibited. Otherwise, these values can serve as a reference for estimating fines for environmental degradation.

As shown in Table 3, the highest costs of degradation are in Pará, Mato Grosso, and Maranhão. On the other hand, for the whole Amazonia, it is worth US\$ 3,131,571.06, equivalent to $0.02 \%$ of the value of production in 2006 . As this is the cost of reduction of 124,214 ha degraded, it is equivalent to US\$25.21/ha/year. It is interesting to note that similar values were found by Pena et al. (2018): the opportunity cost of degraded areas for agricultural activities was US\$ 11.76 per ha/year and for livestock activities US\$ $24.31 \mathrm{per}$ ha/year.
The estimated shadow prices for environmental preservation are recorded in Table 4. They show some highlights. First, all the values were not negative, as expected, indicating that, with eco-efficiency, there is a trade-off: the increase of the forest should generate a reduction in production value. Second, it notes that the magnitudes of their means and their standard deviations are smaller than the values of the shadow price of degraded areas, indicating a smaller variation of the slope of the efficient frontier of the CPP in the direction of $y_{1}$ and $y_{2}$. Therefore, it is evident that increasing the preserved area has a smaller impact on production that reducing degraded. Moreover, the inclination of this tangent line descends as it reduces forested areas. But when the tangent and the shadow price of environmental preservation are null, the unit has slacks and is designed in the call weak efficient frontier, indicating potential to increase the forested area without changing the level of production.

The analysis by state shows that Amazonas has the highest shadow price to expand the preserved forest, while Mato Grosso and Maranhão have the lowest shadow prices. The regional average was US\$1.71/ha/year with a standard deviation equivalent to 1.28 .

The shadow prices have allowed estimation of the opportunity costs of environmental preservation. These were assessed following the same procedure used in the estimation of environmental degradation costs. The best-fitting trend curve was $P_{y_{2}}=1.1402\left(y_{2}^{0.0442}\right)$ that indicates that these prices grow at a rate of 0.0442 as one hectare of preserved forest increases. Calculating the defined integral of the equation that represents the relationship between the shadow price $\left(P_{y_{2}}\right)$ and the preserved land $\left(y_{2}\right)$ in an interval (0.1, the value of the municipal forest preserved in ha) led to two important opportunity costs of forest preservation, shown in Table 4: 
Table 4 Shadow price, cost of forest conservation and emissions avoided in tons of carbon to the fulfillment of the $80 \%$ target of the total area

\begin{tabular}{|c|c|c|c|c|c|c|}
\hline States & $\begin{array}{l}\text { Shadow Price of } \\
\text { Preservation in } \\
\text { US } \$ / \text { ha }\end{array}$ & $\begin{array}{l}\text { Current } \\
\text { Preserved } \\
\text { Areas (ha) }\end{array}$ & $\begin{array}{l}\text { Cost of Current } \\
\text { Preserved Areas } \\
\text { (US\$) }\end{array}$ & $\begin{array}{l}\text { Cost of Current } \\
\text { Preserved Areas } \\
\text { per hectare at } \\
\text { US\$ }\end{array}$ & $\begin{array}{l}\text { Total Cost of } \\
\text { Preserving } 80 \% \\
\text { of the Area of } \\
\text { Property in US\$ }\end{array}$ & $\begin{array}{l}\text { Emissions of Carbon } \\
\text { Avoided in Tons with } \\
80 \% \text { of the Area of } \\
\text { Property }\end{array}$ \\
\hline Rondônia & 2.02 & $2,856,050.56$ & $5,116,854.08$ & 1.79 & $12,472,052.79$ & $6,544,681.38$ \\
\hline Acre & 467.1 .82 & $2,145,881.38$ & $3,962,903.40$ & 1.85 & $5,259,600.06$ & $2,738,149.17$ \\
\hline Amazonas & 2.17 & $1,777,847.90$ & $3,183,322.96$ & 1.79 & $5,296,890.28$ & $2,846,952.38$ \\
\hline Roraima & 1.52 & $766,277.63$ & $1,369,760.04$ & 1.79 & $2,512,931.85$ & $1,332,804.81$ \\
\hline Pará & 1.86 & $8,533,522.49$ & $15,634,474.54$ & 1.83 & $34,553,348.65$ & $17,790,056.59$ \\
\hline Amapá & 1.66 & $384,886.10$ & $678,943.99$ & 1.76 & $1,259,058.55$ & $678,059.88$ \\
\hline Tocantins & 1.69 & $640,709.71$ & $1,104,501.06$ & 1.72 & $3,896,278.72$ & $2,086,005.39$ \\
\hline Maranhão & 1.45 & $848,320.53$ & $1,448,291.47$ & 1.71 & $7,494,866.21$ & $4,065,895.80$ \\
\hline Mato Grosso & 1.26 & $14,249,907.80$ & $26,944,014.98$ & 1.89 & $48,145,635.65$ & $24,228,572.46$ \\
\hline Biome Total & $1.71(1.28)$ & $32,203,404.10$ & $59,443,066.52$ & 1.85 & $120,890,662.76$ & $62,311,177.86$ \\
\hline
\end{tabular}

(i) The total cost of current preserved areas has been estimated at US\$59,443,066.52. Therefore, as the total preserved area recorded in the census is $32,203,404.10$ ha, the unit cost per ha is US\$1.85/year.

(ii) The total cost of preserving $80 \%$ of the area of the property, as the law requires, has been estimated at US\$120,890,662, which is compatible with the preservation of $64,234,327$ ha. Therefore, the unitary cost is US\$ $1.88 / \mathrm{ha} /$ year. This cost represents $1.7 \%$ of the annual income of the producers of the Biome studied. Thus, it is evident that the legal requirement to preserve $80 \%$ of the property area has an opportunity cost higher than the opportunity cost of degraded land, which, as recorded, represents $0.02 \%$ of the annual income of the production value in 2006.

In addition, the values of the costs of forest preservation can be interpreted as the cost of generating free positive externalities. This is a small part of the countless environmental benefits, without considering the impact of the preserved forest on biodiversity, conservation of water resources, emission of greenhouse gases, global climate changes, etc. Thus, if negative externalities are to be internalized (fined), positive externalities must be compensated.

These reimbursements for environmental services provided by farmers can be operationalized through the Clean Development Mechanism (CDM) established by the Kyoto Conference, Japan, in 1997. By way of the CDM, a developed country can, via financial compensation to developing countries, discount its debt in the event that its gas emissions exceed the quotas established in this conference. This compensation primarily considers the benefits of preservation, resulting from carbon sequestration.

The quantification of carbon (C) captured by tropical forests, across the photosynthesis that releases oxygen as a by-product, is a controversial issue. Diverse research estimates values ranging from 70 to 191 tonnes of $\mathrm{C}$ per ha (hereafter tC/ha) (Margulis 2003; Fearnside 2002). For Lemos et al. (2010), it is believed that at 100 years, the forest reaches a steady state, with a sequestration rate of $0.97 \mathrm{tC} / \mathrm{ha} /$ year.

Our work adopted the latter value to estimate the carbon emissions avoided with the preservation of $80 \%$ of the total area of the rural property. However, it is necessary to emphasize that this value considers only the avoided emissions of carbon related to forest preservation, not taking into account the other positive externalities of forest preservation.

The last column of Table 4 shows the carbon emissions avoided with the preservation of $80 \%$ of the total area of the properties by states. It indicates that the highest values of annual avoided emissions correspond to the municipalities of Mato Grosso and Pará, while Amapá has the lowest value. The sum of the region stood at 62,311,177 tons of C.

According to the Brazilian National Economic and Social Development Bank (BNDES 1999), the estimated market value of certified emission reductions (CER) of greenhouse gases is between US\$ 5.00 and US\$ 15.00 per ton of carbon reduced. By taking the minimum value (US\$ 5.00), the amount associated with compensation for carbon sequestration in $80 \%$ of the areas of the properties reaches US $\$ 311,555,889.30,157 \%$ higher than needed to cover the total cost of preservation of $80 \%$ of the property area (US\$ 120,890,662.76).

\section{Conclusions}

This study is a collaborative effort to estimate an ecoefficiency index, shadow prices, costs of degradation, and 
environmental conservation in the biome of Amazonia. We use the theory of production and Data Envelopment Analysis with directional distance functions. It fills an important gap in the study of economic and environmental efficiency and pricing of positive and negative externalities in Brazilian agriculture.

The results indicate that on average the analyzed counties can raise production and forest areas by $38 \%$ and reduce degraded areas and inputs in the same proportion. Thus, growth in world demand for food, fiber, and biofuels, due to population growth, urbanization, and income growth, can be addressed in a more sustainable way. In addition, the ecoefficiency indices reinforce the initial hypothesis that the formulation of policies consistent with the maximization of social welfare is possible, to optimize both economic and environmental objectives. Therefore, it can be concluded that the discussion of economic and environmental issues does not necessarily result in a zero-sum game.

The shadow prices of degraded land allowed to estimate the opportunity costs of this externality. This resulted in $0.04 \%$ of the annual output value. Therefore, internalization of that cost should not be a major problem for the ecoefficient producer. Likewise, the total cost of preserving $80 \%$ of the property area indicated $1.7 \%$ of the annual income of the Biome producers studied, too low to compensate.

Therefore, the main conclusion of this work is that the internalization of negative and positive externalities of agricultural production in the Amazonia biome should generate a positive balance for farmers. Answering the last research question in this paper, we can deduce that more sustainable agriculture does not make agricultural production economically unfeasible in the region.

In addition, the reimbursement for damages avoided by carbon sequestration of preserving $80 \%$ of the property area would generate sufficient revenue to cover this cost of degraded land. Consequently, it is plausible that the implementation of the Brazilian emissions trading Kyoto mechanism can solve the problem of compensation of free environmental services generated by producers who preserve forests in the biome studied.

We should conclude this article stating that, while there are clearly oversimplifications on the theoretical framework laid down above, no doubt it provides reference values within which important issues are discussed. Of course, a desirable understanding of the analysis is very complex. The present article is a point of departure for further research. In later works, a more realistic model should be designed, including data from the 2017 agricultural census, which was released in 2019. Since the coronavirus pandemic is already making considerable impacts on the biome, an up-to-date rethinking of the region seems to be required.
Acknowledgements The authors are grateful to Leopoldo Costa Junior, Danielle Sandi Pinheiro, Neantro Saavedra-Rivano, Rodrigo Andrés de Souza Peñaloza, and Marcondes M. de Araujo for comments and suggestions.

Author contribution CRP designed the work, acquired the data, implemented the models, analyzed results, and was a major contributor in writing the manuscript. JRT conceived the study, performed the analysis and interpretation of the results, and contributed in the writing of the manuscript. HK analyzed the data, interpreted the results, and contributed in the writing of the manuscript. All the authors read and approved the final manuscript.

Funding Carlos Rosano-Peña received the financial support of the Support Research Foundation of the Federal District (FAP-DF), and Joanílio Rodolpho Teixeira received the financial support of the Brazilian National Council for Scientific and Technological Development (CNPq).

Availability of data and materials The data used in this study is available at the Brazilian Institute of Geography and Statistics website: (https://www.ibge.gov.br/estatisticas/economicas/ agricultura-e-pecuaria/9827-censo-agropecuario.html?=\& $\mathrm{t}=$ resultados)

\section{Declarations}

Ethical approval Not applicable

Consent to participate Not applicable

Consent to publish Not applicable

Competing interests The authors declare no competing interests.

\section{References}

Aladejana OO, Salami AT, Adetoro OIO (2018) Hydrological responses to land degradation in the Northwest Benin Owena River Basin, Nigeria. J Environ Manag 225:300-312. https://doi.org/10.1016/j.jenvman.2018.07.095

Arandia A, Aldanondo-Ochoa A (2011) Pollution shadow prices in conventional and organic farming: an application in a Mediterranean context. Span J Agric Res 9(2):363-376

Areal FJ, Tiffin R, Balcombe KG (2012) Provision of environmental output within a multi-output distance function approach. Ecol Econ 78(1):47-54

Ball E, Färe R, Grosskopf S, Zaim O (2005) Accounting for externalities in the measurement of productivity growth: the Malmquist cost productivity measure. Struct Chang Econ Dyn 16(3):374-394

Barreto P, Jr S, Anderson CA, Salomão R, Wiles J, Nogueron R (2006) Human pressure on the brazilian amazon forest biome. Imazon 3(1): $1-6$

BNDES (1999) Greenhouse effect and the united nations framework convention on climate change. Technical report, Banco Nacional de Desenvolvimento Econômico e Social e Ministério da Ciência e Tecnologia, Rio de Janeiro

Bravo-Ureta BE, Solís D, López VHM, Maripani JF, Thiam A, Rivas T (2006) Technical efficiency in farming: a meta-regression analysis. J Product Anal 27(1):57-72

Caiado RGG, de Freitas Dias R, Mattos LV, Quelhas OLG, Filho WL (2017) Towards sustainable development through the perspective 
of eco-efficiency - a systematic literature review. J Clean Prod 165(1):890-904

Callens I, Tyteca D (1999) Ecol Econ 28(1):41-53

Chung Y, Färe R, Grosskopf S (1997) Productivity and undesirable outputs: a directional distance function approach. J Environ Manag 51(3):229-240

Darku A, Malla S, Tran K (2013) Historical Review of Agricultural Productivity Studies. Technical report, CAIRN Research Network, Alberta

Domingues MS, Bermann C (2012) The arc of deforestation in Amazon: from livestock farming to soybean. Ambiente Sociedade $15(2): 1-22$

FAO (2009) How to feed the world in 2050. Technical report, High Level Expert Forum, Rome

Färe R, Grosskopf S (2000) Theory and application of directional distance functions. J Product Anal 13(2):93-103

Färe R, Grosskopf S (2005) New directions: efficiency and productivity. Kluwer Academic Publishers, New York

Färe R, Grosskopf S, Weber WL (2006) Shadow prices and pollution costs in U.S. agriculture. Ecol Econ 56(1):89-103

Fearnside PM (2002) Avanća Brasil: environmental and social consequences of Brazil's planned infrastructure in Amazonia. Environ Manag 30(6):735-747

Graves A, Morris J, Deeks L, Rickson R, Kibblewhite M, Harris J, Farewell T, Truckle I (2015) The total costs of soil degradation in England and Wales. Ecol Econ 119:399-413. https://doi.org/10. 1016/j.ecolecon.2015.07.026

Grosskopf S (1986) The role of the reference technology in measuring productive efficiency. Econ J 96(382):499

IBGE (2010) Agribusiness census 2006. Technical report, Instituto Brasileiro de Geografia e Estatística, Rio de Janeiro

IPEA (2013) Characterization and analysis of the dynamics of farming in the Brazilian Amazon: an analysis of the agribusiness census 2006. Technical report, Instituto De Pesquisa Econômica Aplicada

Kuosmanen T, Kortelainen M (2005) Measuring eco-efficiency of production with data envelopment analysis. J Ind Ecol 9(4):5972

Kust G, Andreeva O, Cowie A (2017) Land degradation neutrality: concept development, practical applications and assessment. J Environ Manag 195:16-24

Lampe HW, Hilgers D (2015) Trajectories of efficiency measurement: a bibliometric analysis of DEA and SFA. Eur J Oper Res 240(1):121

Lee JD, Park JB, Kim TY (2002) Estimation of the shadow prices of pollutants with production/environment inefficiency taken into account: a nonparametric directional distance function approach. J Environ Manag 64(4):365-375

Lemos A, Vital MHF, Pinto MAC (2010) Forests and UN's Intergovernmental Panel on Climate Change. BNDES Setorial 32(1):670-682

Margulis S (2003) Causes of deforestation in the Brazilian Amazon. Technical report, Banco Mundial, Brasília
Medrilzam M, Smith C, Aziz AA, Herbohn J, Dargusch P (2017) Smallholder farmers and the dynamics of degradation of peatland ecosystems in Central Kalimantan, Indonesia. Ecol Econ 136:101113

Padrão GA, Campos SAC, Lirio VS, Da Silva M (2012) Environmental efficiency and opportunity cost of the forest code for the Amazon. Technical report, sRIO+20 - International Society for Ecological Economics Conference, Rio de Janeiro

Pena CR, Serrano ALM, de Britto PAP, Franco VR, Guarnieri P, Thomé KM (2018) Environmental preservation costs and ecoefficiency in Amazonian agriculture: application of hyperbolic distance functions. J Clean Prod 197(1):699-707

Picazo-Tadeo AJ, Prior D (2009) Environmental externalities and efficiency measurement. J Environ Manag 90(11):3332-3339

Picazo-Tadeo AJ, Gómez-Limón JA, Reig-martínez E (2011) Assessing farming eco-efficiency: A Data Envelopment Analysis approach. J Environ Manag 92(4):1154-1164

Picazo-Tadeo AJ, Beltrản-Esteve M, Gómez-Limón JA (2012) Assessing eco-efficiency with directional distance functions. Eur J Oper Res 220(3):798-809

Pittman RW (1983) Multilateral productivity comparisons with undesirable outputs. Econ J 93(372):883

Reed M, Stringer L, Dougill A, Perkins J, Atlhopheng J, Mulale K, Favretto N (2015) Reorienting land degradation towards sustainable land management: linking sustainable livelihoods with ecosystem services in rangeland systems. J Environ Manag 151:472-485. https://doi.org/10.1016/j.jenvman.2014.11.010

Reinhard S, Lovell CK, Thijssen GJ (2000) Environmental efficiency with multiple environmentally detrimental variables; estimated with SFA and DEA. Eur J Oper Res 121(2):287-303

Simar L, Wilson PW (2007) Estimation and inference in twostage, semi-parametric models of production processes. J Econ 136(1):31-64

Sutton PC, Anderson SJ, Costanza R, Kubiszewski I (2016) The ecological economics of land degradation: impacts on ecosystem service valuesx. Ecol Econ 129:182-192. https://doi.org/10.1016/j. ecolecon.2016.06.016

Suzigan LH, Peña CR, Guarnieri P (2020) Eco-efficiency assessment in agriculture: a literature review focused on methods and indicators. J Agricul Sci 12(7):118. https://doi.org/10.5539/jas. v12n7p118

Tyteca D (1996) On the measurement of the environmental performance of firms - a literature review and a productive efficiency perspective. J Environ Manag 46(3):281-308

Val AL, Santos GMd (2011) Group of strategic studies of the amazon, working paper. TOMO IV In Press

WCED (1987) Our common future. The brundtland report. Technical report, World Commission on Environment and Development, Oxford

Publisher's note Springer Nature remains neutral with regard to jurisdictional claims in published maps and institutional affiliations. 